\title{
Combining Schwann Cell Bridges and Olfactory-Ensheathing Glia Grafts with Chondroitinase Promotes Locomotor Recovery after Complete Transection of the Spinal Cord
}

\author{
Karim Fouad, ${ }^{1}$ Lisa Schnell, ${ }^{2}$ Mary B. Bunge, ${ }^{3,4,5}$ Martin E. Schwab, ${ }^{2}$ Thomas Liebscher, ${ }^{2}$ and Damien D. Pearse ${ }^{3,5}$ \\ ${ }^{1}$ University of Alberta, Faculty of Rehabilitation Medicine, Edmonton, Canada T6G 2G4, ${ }^{2}$ Brain Research Institute, University of Zurich, and Department of \\ Biology, Swiss Federal Institute of Technology, 8006 Zurich, Switzerland, and ${ }^{3}$ The Miami Project to Cure Paralysis, ${ }^{4}$ Departments of Cell Biology and \\ Anatomy and ${ }^{5}$ Neurological Surgery, University of Miami School of Medicine, Miami, Florida 33101
}

\begin{abstract}
Numerous obstacles to successful regeneration of injured axons in the adult mammalian spinal cord exist. Consequently, a treatment strategy inducing axonal regeneration and significant functional recovery after spinal cord injury has to overcome these obstacles. The current study attempted to address multiple impediments to regeneration by using a combinatory strategy after complete spinal cord transection in adult rats: (1) to reduce inhibitory cues in the glial scar (chondroitinase $A B C),(2)$ to provide a growth-supportive substrate for axonal regeneration [Schwann cells (SCs)], and (3) to enable regenerated axons to exit the bridge to re-enter the spinal cord (olfactory ensheathing glia). The combination of SC bridge, olfactory ensheathing glia, and chondroitinase ABC provided significant benefit compared with grafts only or the untreated group. Significant improvements were observed in the Basso, Beattie, and Bresnahan score and in forelimb/hindlimb coupling. This recovery was accompanied by increased numbers of both myelinated axons in the SC bridge and serotonergic fibers that grew through the bridge and into the caudal spinal cord. Although prominent descending tracts such as the corticospinal and reticulospinal tracts did not successfully regenerate through the bridge, it appeared that other populations of regenerated fibers were the driving force for the observed recovery; there was a significant correlation between numbers of myelinated fibers in the bridge and improved coupling of forelimb and hindlimb as well as open-field locomotion. Our study tests how proven experimental treatments interact in a well-established animal model, thus providing needed direction for the development of future combinatory treatment regimens.
\end{abstract}

Key words: spinal cord injury; regeneration; locomotion; plasticity; rat; treatment combination

\section{Introduction}

Spinal cord injury (SCI) in adult mammals comprises complex pathophysiological processes characterized by extensive cell death, incomplete self-repair, and limited axonal regeneration (for review, see Schwab and Bartholdi, 1996). These processes suggest that a combination of strategies may be required to prevent ongoing tissue damage and promote regrowth and reconnection of axons.

Successful experimental interventions used to promote regeneration of axotomized axons have relied on the following: (1) blockade of inhibitory cues within the injury site involving the glial scar and myelin [e.g., chondroitin sulfate proteoglycans

\footnotetext{
Received Aug. 30, 2004; revised Dec. 14, 2004; accepted Dec. 16, 2004.

This study was supported by the Alberta Heritage Foundation for Medical Research, the Canadian Foundation for Innovation, the International Spinal Research Trust, and National Institute of Neurological Disorders and Stroke Grant 09923 (M.B.B.). M.B.B., M.E.S., D.D.P., and L.S. were supported by the Christopher Reeve Paralysis Foundation (CRPF) and were members of the CRPF Research Consortium. We thank Kendra Bojarski and Romana Vavrek for help with animal care, Mark Ballerman for help during the experiments, Yelena Pressman for help in cell culture, Raisa Puzis and Margaret Bates for preparation and analysis of plastic-embedded tissue, Maneesh Garg for help with imaging, and Dr. Ty Hazlett (CytoTherapeutics, Providence, Rl) for the polymer channels.

Correspondence should be addressed to K. Fouad, University of Alberta, Faculty of Rehabilitation Medicine, 3-48 Corbett Hall, Edmonton, Alberta, Canada T6G 2G4. E-mail: karim.fouad@ualberta.ca.

D0I:10.1523/JNEUROSCI.3562-04.2005

Copyright $\odot 2005$ Society for Neuroscience $\quad$ 0270-6474/05/251169-10\$15.00/0
}

(CSPGs) and NOGO, respectively] (Fawcett and Asher, 1999; Brosamle et al., 2000; Merkler et al., 2001; Bradbury et al., 2002; Li and Strittmatter, 2003; Silver and Miller, 2004); (2) supplementation of growth-promoting cues such as neurotrophic factors (Schnell et al., 1994; Mocchetti and Wrathall, 1995; Kobayashi et al., 1997; Ye and Houle, 1997; Blesch and Tuszynski, 2003), extracellular matrix components, or biopolymers (Novikova et al., 2002, 2003; Woerly et al., 2004); (3) or cellular transplantation (Li et al., 1997; Xu et al., 1997; Ramón-Cueto et al., 1998, 2000; Takami et al., 2002) (for review, see Bunge and Pearse, 2003); and (4) stimulation with agents capable of facilitating or activating the intrinsic capacity of neuronal regeneration programs (for review, see Pearse, 2004), including the elevation of intracellular cAMP (Neumann et al., 2002; Qiu et al., 2002) or manipulation of the Rho pathway (Dergham et al., 2002; Fournier et al., 2003).

Whereas treatments targeting these processes have individually proven efficacious in facilitating regeneration and functional recovery after SCI, the number of regenerating axons is generally small and functional recovery modest, illustrating the need to overcome multiple factors that limit axon growth. Therefore, it is conceivable that a combination of strategies may bring about increased axonal growth and functional recovery. In searching for the optimal combination strategy for SCI repair, a number of 
studies have demonstrated the additive potential of two or more therapeutic approaches. Such strategies combine cell grafting with approaches including neuroprotective agents (Pearse et al., 2004b), exogenous or cellular overexpressed growth factors (Xu et al., 1995a; Bregman et al., 1997; Menei et al., 1998; Coumans et al., 2001), elevation of cAMP (Lu et al., 2004; Nikulina et al., 2004; Pearse et al., 2004a), or scar-reducing enzymes (Chau et al., 2004). Combinatory pharmacological therapies have also been tested (Guth et al., 1994; Mu et al., 2000). With regard to Schwann cell (SC) implants specifically, the addition of methylprednisolone (Chen et al., 1996), neurotrophins (Xu et al., 1995a; Menei et al., 1998; Weidner et al., 1999; Bamber et al., 2001), olfactory ensheathing glia (OEG) (Ramón-Cueto et al., 1998), or elevated cAMP (Pearse et al., 2004a) substantially improved axonal regeneration.

The current study applies a combination of interventions by reducing inhibitory cues of the scar tissue (chondroitinase $A B C$ ), providing a growth-supportive substrate for axonal regeneration (SC bridge) and enabling regenerated axons to leave the bridge (OEG) in adult rats with complete spinal cord transection.

\section{Materials and Methods}

\section{Cell culture}

Schwann cells. SCs were obtained from sciatic nerves of adult female Fischer rats (Harlan, Indianapolis, IN) as described previously (Morrissey et al., 1991). Nerves were cut into small pieces and placed in culture dishes in DMEM/10\% heat-inactivated fetal bovine serum (FBS) without mitogens. After 2 weeks, the pieces were transferred to new dishes where they were enzymatically dissociated and then replated in DMEM $/ 10 \%$ FBS supplemented with three, rather than two, mitogens: bovine pituitary extract ( $2 \mathrm{mg} / \mathrm{ml}$; Invitrogen Corporation, Carlsbad, CA), forskolin $(0.8 \mu \mathrm{g} / \mathrm{ml})$, and heregulin (2.5 nM; Genentech, San Francisco, CA) as described previously (Meijs et al., 2004). The purity of the SCs assessed by using the S100 and Hoechst stains was 95-98\%.

Olfactory ensheathing glia. Highly purified cultures of OEG were prepared from the nerve fiber layer of the olfactory bulb of adult female Fischer rats (Harlan) using a procedure modified from one described previously (Ramón-Cueto et al., 1998). The pia was removed and care was taken to minimize the inclusion of non-nerve fiber layer bulb tissue. OEG were dissociated and, unlike the method of Ramón-Cueto et al. (1998), were exposed for $5 \mathrm{~d}$ to forskolin $(0.8 \mu \mathrm{g} / \mathrm{ml})$ and pituitary extract $(2 \mathrm{mg} / \mathrm{ml})$ in DMEM/F-12/10\% FBS before purification by $\mathrm{p} 75$ immuno-panning as described previously (Takami et al., 2002). The OEG were used after 2 passages (at $\sim 18 \mathrm{~d}$ after extraction from the olfactory bulb). A second period in mitogens preceded harvesting at confluency for transplantation. Checking the purity was similar to SCs except that p75, rather than S100, was used with Hoechst nuclear staining. Purity was found to be between 94 and $98 \%$.

Preparation of the cells for grafting. Cultured SCs or OEG were harvested in DMEM/F-12 medium. Before transplantation, OEG were trypsinized to remove them from the dishes, and the cells were counted using a hemocytometer. SCs were resuspended in a 60:40 (v/v) solution of DMEM/F-12:Matrigel (BD Biosciences, San Jose, CA) immediately before grafting. Each animal received a total of $5 \times 10^{6} \mathrm{SCs}$ for transplantation. OEG were resuspended in aliquots of $4 \mu \mathrm{l}$ of DMEM/F-12 medium containing $4 \times 10^{5}$ cells immediately before spinal cord injection.

\section{Surgical procedures}

The experiments were performed using adult female Fischer rats (165180 g; Charles River Laboratories, Wilmington, MA). All rats were kept at a $12 \mathrm{~h}$ light/dark cycle and received water and food ad libitum. A complete injury model ensured that regeneration of axons could be identified definitively.

The experiment was approved by the animal welfare committee at the University of Alberta. After arrival, the rats were handled for 2 weeks and

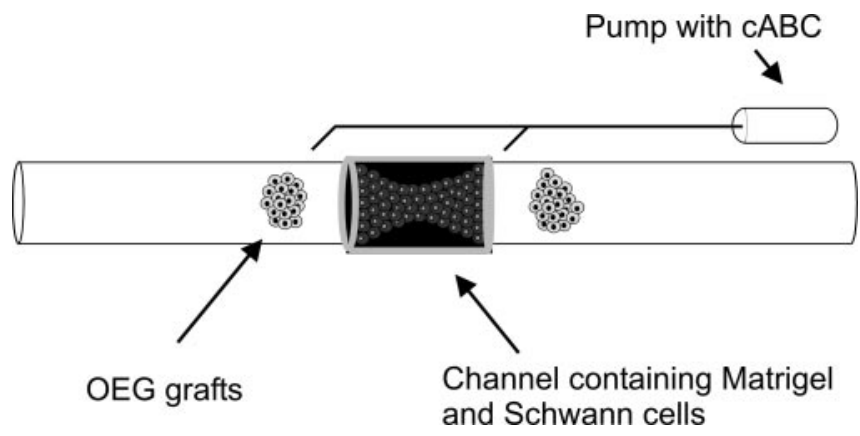

Figure 1. Experimental design for the cell grafting and $C A B C$ treatment after the removal of the thoracic 8 segment of the spinal cord.

trained to drink Ensure (complete meal replacement, Ross products division; Abbott Laboratories, Irving, TX) from a syringe.

For the different treatment combinations, the rats were divided into three experimental groups: (1) control group with transection and Matrigel-only bridge $(n=8)$; (2) transection with SCs and Matrigel bridge, rostrocaudal OEG grafts, and pump delivery of galactosidase and mouse IgG (referred to as graft-only group; $n=7$ ); and (3) transection with SC:Matrigel bridge, rostrocaudal OEG grafts, and pump delivery of chondroitinase $\mathrm{ABC}$ and mouse IgG (referred to as $\mathrm{CABC}$ group; $n=5$ ). The treatments are illustrated in Fig. 1.

The IgG was accommodated into the experiment as a control for an additional treatment group, which is not reported here.

\section{Spinal cord transection and Schwann cell grafting}

Animals were anesthetized with a subcutaneous injection of Hypnorm (120 $\mu \mathrm{l}$ per $200 \mathrm{~g}$ body weight; Janssen Pharmaceutics, Beerse, Belgium) and Midazolam $(0.75 \mathrm{mg}$ in $150 \mu \mathrm{l} / 200 \mathrm{~g}$ body weight; $750 \mu \mathrm{l}$ total volume diluted with $\mathrm{H}_{2} \mathrm{O}$; Sabex, Boucherville, Quebec, Canada). Eye lubricant (Tears Naturale; Alcon, Mississauga, Ontario, Canada) was applied to protect the eyes from dehydration.

After a laminectomy at the T 7.5-9 vertebral level, the meningeal membranes were severed along with the dura mater, the spinal cord was completely transected, and a $4 \mathrm{~mm}$ region of spinal cord encompassing T8 was removed. The rostral and caudal stumps were lifted after removal of the spinal cord segment to ensure complete discontinuity. All spinal roots visible in the injury gap were removed, and bleeding was stopped using Gelfoam (Upjohn, Kalamazoo, MI). Thereafter, $\sim 2 \times 10^{5}$ OEG were drawn into a glass pipette with a tip diameter of $150-200 \mu \mathrm{m}$ mounted onto a $5 \mu \mathrm{l}$ Hamilton syringe (Hamilton, Reno, NV) attached to a micromanipulator. The cells were deposited into two injection sites at the rostral as well as the caudal stump, $\sim 2 \mathrm{~mm}$ from the lesion, at 300 $\mu \mathrm{m}$ lateral to the midline, and to a depth of $800 \mu \mathrm{m}$. A volume of $1 \mu \mathrm{l}$ containing $\sim 10^{5}$ OEG in DMEM/F-12 was grafted into each site. Next, the rostral cord stump was inserted $2 \mathrm{~mm}$ into a $6 \mathrm{~mm}$-long hollow, semipermeable 60:40 polyacrylonitrile/polyvinylchloride copolymer guidance channel (2.6 mm inner diameter, $3.0 \mathrm{~mm}$ outer diameter; provided by T. Hazlett, CytoTherapeutics, Providence, RI), previously cleaned and sterilized (Aebischer et al., 1988). The channel was then drawn back $1 \mathrm{~mm}$ to permit the insertion of the caudal stump $1 \mathrm{~mm}$ into the channel. Opening two small windows that had been crafted into the dorsal surface of the channel before implantation allowed $30 \mu \mathrm{l}$ of SCs suspended in a 60:40 (v/v) solution of DMEM/F-12:Matrigel to slowly fill the channel. The windows were then closed and sealed with Matrigel, and surgery was halted for $5 \mathrm{~min}$ to allow semisolidification of the Matrigel-SC cable at $37^{\circ} \mathrm{C}$.

In addition to the drug delivery using pumps (see below), immediately adjacent to the lesion, the wound was rinsed with chondroitinase or vehicle. The surgeon was blinded for both kinds of treatments.

\section{$c A B C$ delivery}

A double catheter was constructed by sealing two fine catheters (ReCathCo, Allison Park, PA) into a connecting tube from the minipumps (model 2002; Alzet, Cupertino, CA). The ends were cut to provide deliv- 
ery at the rostral and caudal spinal cord outside the guidance channel, thus ensuring the delivery of the chondroitinase (cABC; Seikagaku America, East Falmouth, MA) to the sites of scarring at the SC bridge/ host spinal cord interfaces. The tubing was fixed with sutures to the caudal musculature. The connected minipump contained sterile $0.9 \%$ $\mathrm{NaCl}$ to keep the catheters clear during the intervals between cABC injections ( $2 \mu \mathrm{l}$ of $10 \mu \mathrm{g} / \mathrm{ml} \mathrm{cABC}$ ). Injections were performed every other day for 4 weeks under short isoflurane anesthesia. Pumps were placed into skin pouches on the back of the rats and kept in position with sutures. Finally, the overlying muscles were sutured in layers, and the skin was closed with wound clips.

\section{Antibody delivery}

A fine (32 gauge) intrathecal catheter (ReCathCo) was inserted subdurally from the lumbar level to its delivery site at the caudal SC bridge/ host spinal cord interface. The catheter supplied the antibody (model 2002; Alzet) to the injury site for 4 weeks. Pumps contained antibody (IgG) at a concentration of $3 \mathrm{mg} / \mathrm{ml}$ in PBS, and the delivery rate of the pumps was $0.6 \mu \mathrm{l} / \mathrm{h}(=1.8 \mu \mathrm{g} / \mathrm{h})$.

After surgery, the animals were kept on a thermostatically regulated heating pad until completely awake. The analgesic Buprenex (buprenorphine; Reckitt and Colman, Richmond, VA) was administered subcutaneously $(0.03 \mathrm{mg} / \mathrm{kg})$ immediately after operation and every $8 \mathrm{~h}$ for $74 \mathrm{~h}$. Ringer's solution ( $4 \mathrm{ml}$ ) was given subcutaneously daily for the first week and at later stages if animals showed signs of dehydration. The antibiotic, cefazolin ( $5 \mathrm{mg} / \mathrm{kg}$, s.c.; Novopharm, Toronto, Ontario, Canada) was administered once each day for $4 \mathrm{~d}$ starting at $1 \mathrm{~d}$ before surgery.

Bladders were expressed three times per day until the voiding reflex of the bladder was reestablished. For 2 weeks after injury, up to $1 \mathrm{ml}$ of Ensure (chocolate or vanilla) was fed to each rat twice each day. After 2 weeks, pumps were exchanged under isoflurane anesthesia, and at 4 weeks, pumps and catheters were removed.

\section{Evaluating chondroitin sulfate digestions}

To demonstrate that $\mathrm{CABC}$ degraded chondroitin sulfate at the host cord/SC graft interface, three monoclonal antibodies that recognize either intact or digested chondroitin sulfate were used for immunochemical staining on alternative spinal cord sections of 2 week cABC-treated $(n=2)$ or galactosidase-treated grafted animals $(n=3)$. One antibody, 2B6 (1:150; Seikagaku America), recognizes an epitope created after CABC degradation of chondroitin-4 sulfate and does not identify the intact form (Moon et al., 2001). The other antibodies used were CS-56 (1:500; Sigma-Aldrich, St. Louis, MO), which recognizes an epitope located on various intact chondroitin sulfate glycosaminoglycan chains, and 1D1 (1:200; Developmental Studies Hybridoma Bank, University of Iowa, Iowa City, IA), which recognizes the CSPG core protein of neurocan (Moon et al., 2002). An increase of $2 \mathrm{~B} 6$ and a reduction in the amount of either CS-56 or 1D1 immunoreactivity at the interface would indicate $\mathrm{CABC}$ efficacy. To measure changes in immunoreactivity intensity of 2B6, CS-56, and 1D1 at the caudal host cord/SC graft interface, 40 $\mu \mathrm{m}$ sagittal sections at every $200 \mu \mathrm{m}(10-12$ sections/animal) were evaluated using computer-assisted microscopy and MetaMorph software (Universal Imaging Corporation, West Chester, PA). In each section, images encompassing an $800 \times 800 \mu \mathrm{m}$ area equally overlapping both SC and the contiguous host cord region of the caudal interface and symmetrical to a line drawn through the center of the cord were evaluated. Immunoreactivity intensity (arbitrary units; higher value indicating greater staining) for each antibody at the caudal interface was determined per animal by averaging measured intensity values across all sections examined.

\section{Testing locomotor recovery}

Recovery of hindlimb stepping movements was evaluated using several locomotor tests to determine whether recovery was attributable to increased excitability of spinal networks or to partial reestablishment of descending control.

Basso, Beattie, and Bresnahan score. The open-field locomotor score (Basso et al., 1995) was determined by two blinded observers. Before testing, bladders were expressed, because spontaneous bladder contraction often accompanies hindlimb activity. The rats were placed in a trans- parent Plexiglas box $(30 \times 90 \times 120 \mathrm{~cm})$ with a smooth floor and were observed for $4 \mathrm{~min}$. Hindlimb movements immediately after contact with experimenters were disregarded. During the open-field activity, the animals were also video-monitored with a digital camera using a shutter speed of $1 / 250 \mathrm{~s}$ for additional analysis of forelimb/hindlimb coupling.

Forelimb/hindlimb coupling. This analysis adds valuable information to the Basso, Beattie, and Bresnahan (BBB) score, because both the frequency of hindlimb activity and the coordination with the forelimb during walking sequences are taken into account. To quantify forelimb/ hindlimb coupling, the order of steps made by an ipsilateral forelimb/ hindlimb pair was recorded. Percentage scores of forelimb/hindlimb coupling were determined by dividing the number of correct couplings (in which a forelimb step was followed by a hindlimb step, or vice versa) by the total number of couplings in the sequence (the number of steps in the sequence minus one). For this analysis, five video sequences per animal, with a minimum of six forelimb steps, were chosen.

Role of sensory feedback on hindlimb movement. A major issue when testing locomotor recovery is to resolve whether hindlimb movements are triggered by volitional drive or by sensory feedback from the hindlimbs passively sliding over the ground. To investigate this question, we tested open-field locomotion on different surfaces. In addition to the smooth Plexiglas surface in the open field described above, we used a slippery surface and a rough surface. These tests are new and have not been described in the literature. To test locomotion on a slippery surface, we used a Plexiglas runway $(80 \times 10 \mathrm{~cm}$, with $10 \mathrm{~cm}$ high walls $)$ with its walking surface covered by a thin layer of paraffin oil. On this surface, forward propulsion was reduced to "stationary walking" when rats performed stepping movements with their forelimbs. Therefore, the amount of sensory feedback to the hindlimbs from passive sliding was limited. Events where forelimb and hindlimb movements occurred in a stepping sequence were scored. The test was performed once at 9 weeks after transection and only in animals with BBB scores of 6 and higher.

To test the influence of increased sensory feedback, the rats were placed on a rough carpet, and the forelimb/hindlimb couplings were analyzed as described during open-field locomotion. This test was also performed at 9 weeks after transection; all animals were tested on the carpet.

\section{Sensory testing}

Each rat was wrapped in a towel and held such that its covered head could move freely, and the hindlimbs remained exposed. Because the rats were used to handling and restraining, they remained calm, and five different locations on dermatomes that lost their ascending projections (i.e., base of the tail, skin above the femur on both hindlegs, and the dorsal surfaces of both hindpaws) were stimulated with a set of von Frey hairs (Stoelting, Wood Dale, IL). The von Frey hair was placed on the skin and pressure applied (target force, $0.04-1 \mathrm{~g}$ ), so that it would slightly bend and then be directly removed. The stimulation started with a low intensity (small hair diameter; $0.04 \mathrm{~g}$ target force) and was repeated three times. If no twitch response was observed, the next thicker hair was used. The lowest stimulation intensity to produce a response was repeated three times before the sensation threshold was recorded. Repeated stimulations of any given spot were separated by at least $2 \mathrm{~min}$ to avoid desensitization.

\section{Tracing and histology}

At 10 weeks after injury, the corticospinal tract (CST) and reticulospinal tract (RtST) were unilaterally traced under Hypnorm/Midazolam anesthesia (as described above). For the CST tracing, $2 \mu \mathrm{l}$ of biotinylated dextran amine (BDA) [molecular weight (MW), 10,000; D-1956, 10\% in 0.01 M PBS; Molecular Probes, Eugene, OR) were injected into four sites in the sensorimotor cortex using a Hamilton syringe as described previously (Fouad et al., 2001). For tracing of the RtST, a long-necked glass microelectrode mounted onto a Hamilton syringe was stereotaxically guided into the giant nucleus of the reticular formation (coordinates from Paxinos and Watson, 1986). A volume of $0.35 \mu \mathrm{l}$ 5\% Micro Ruby (dextran, tetramethylrhodamine, and biotin; $3000 \mathrm{MW}$; Molecular Probes) was slowly injected over a period of $5 \mathrm{~min}$.

Two weeks after the tracing, the animals were killed with pentobarbital (Euthanyl, Bimeda-MTC; $70 \mathrm{mg} / 100 \mathrm{mg}$ body weight) and transcardially 
perfused with phosphate-buffered $4 \%$ paraformaldehyde $(0.1 \mathrm{M}, \mathrm{pH} 7.4)$ (Takami et al., 2002). The spinal cord and brain were removed and postfixed overnight in the same fixative at $4^{\circ} \mathrm{C}$. The spinal cords were examined under a surgical microscope for continuity of the bridge and the spinal cord and photographed. A 1-mm-thick transverse slice was taken from the middle of the SC bridge and placed in $2 \%$ glutaraldehyde with $100 \mathrm{~mm}$ sucrose in phosphate buffer (PB; $0.05 \mathrm{M}, \mathrm{pH} 7.4)$ for at least $24 \mathrm{~h}$ at $4^{\circ} \mathrm{C}$. This tissue was then further fixed in $1 \%$ buffered osmium tetroxide for 2-16 h, dehydrated, embedded in Epon-Araldite (Electron Microscopy Sciences, Fort Washington, PA), and cut transversely in semithin sections $(1 \mu \mathrm{m})$. These sections were stained with a $1 \%$ toluidine blue-1\% methylene blue- $1 \%$ sodium borate solution to analyze SC bridge histology and to determine the number of myelinated axons and blood vessels therein. The remaining SC bridge and adjacent rostral and caudal spinal cord and brain were cryoprotected in $30 \%$ sucrose in $\mathrm{PB}$ $(0.1 \mathrm{M}, \mathrm{pH}$ 7.4) for at least $24 \mathrm{~h}$, frozen in Tissue-Tek OCT compound (Sakura Finetek, Torrance, CA), and cut into 30- $\mu \mathrm{m}$-thick sagittal sections. Efficacy of the tracing was evaluated in cervical cord sections.

Total numbers of myelinated axons and blood vessels were counted as described previously (Xu et al., 1995b). Briefly, in stained, 1- $\mu$ m-thick transverse plastic sections (three sections from a $1 \mathrm{~mm}$ slice from the center of the SC bridge; $n=6$ per group), the bridge area was outlined and then scanned using a fractionator grid at $630 \times$ magnification (optical fractionator method; West and Collins, 1989). Every blood vessel and every myelinated axon present within each grid square (surface area, $0.028 \mathrm{~mm}^{2}$ ) was counted.

\section{Immunohistochemistry}

The sections chosen for evaluation were postfixed a second time on the slides with $4 \%$ paraformaldehyde, $0.1 \%$ glutaraldehyde, and $0.1 \%$ picric acid for $20 \mathrm{~min}$ and then washed in $0.1 \mathrm{M} \mathrm{PB}$ three times. A quenching step was added by leaving the sections for $10 \mathrm{~min}$ in $50 \% \mathrm{EtOH}$ plus $0.3 \%$ $\mathrm{H}_{2} \mathrm{O}_{2}$, followed by two washing cycles in $\mathrm{PB}$ for 10 min. Blocking was performed with $0.4 \% \mathrm{NaBH}_{4}$ for $10 \mathrm{~min}$. After washing the slides in $\mathrm{PB}$ three times for $20 \mathrm{~min}$, they were incubated with $0.1 \mathrm{M}$ citrate buffer, $\mathrm{pH}$ 4.5 , overnight at $4^{\circ} \mathrm{C}$.

The next day, the slides were warmed to room temperature and microwaved for $1 \mathrm{~min}$ at $600 \mathrm{~W}$, followed by two cycles of $30 \mathrm{~s}$ at $600 \mathrm{Watts}$ in a separate glass container in $200 \mathrm{ml}$ of $\mathrm{H}_{2} \mathrm{O}$. Slides were left to cool for $30 \mathrm{~min}$ and were subsequently blocked in $1 \%$ Top Block gelatin (Juro Supply, Lucerne, Switzerland) for $20 \mathrm{~min}$ [ $200 \mathrm{mg}$ of Top Block in $0.3 \%$ Tris-buffered saline with Triton X-100 (TBS-TX)]. The 5-HT antibody (DiaSorin, Stillwater, MN) was added in a dilution of 1:8000 containing $4 \%$ normal goat serum (NGS) and left on the slides overnight at $4^{\circ} \mathrm{C}$. Slides were washed twice in PB for $10 \mathrm{~min}$ before the second biotinylated goat anti rabbit antibody (1:300 in $0.3 \%$ TBS-TX plus $2 \%$ NGS) was added and left for $45 \mathrm{~min}$ at room temperature. Slides were then rinsed twice in PBS for $10 \mathrm{~min}$, and the ABC elite complex was added for $45 \mathrm{~min}$. After three washing steps of $10 \mathrm{~min}$ each in PBS, they were preincubated with $0.05 \mathrm{M}$ Tris, $\mathrm{pH} 8.0$, for $5 \mathrm{~min}$. Slides were then reacted in $50 \mathrm{ml}$ of $0.05 \mathrm{M}$ Tris plus $25 \mathrm{mg}$ of DAB plus $25 \mu \mathrm{l}$ of $30 \% \mathrm{H}_{2} \mathrm{O}_{2}$ for $\sim 1-2 \mathrm{~min}$. The reaction was stopped in ice-cold $\mathrm{PBS}$, followed by two washes in $\mathrm{PB}$ for 10 min and one rinse in water. Slides were dried overnight and coverslipped.

\section{5-HT fiber counts}

The number of 5-HT-positive fibers caudal to the lesion site was analyzed quantitatively using a light microscope with bright-field illumination at a final magnification of $400 \times$. Because alternating $25 \mu \mathrm{m}$ sagittal sections were cut to visualize CST and RtST fibers and for spare sections, the sections chosen for the analysis of 5-HT-positive fibers were separated by $75 \mu \mathrm{m}$ intervals. This minimized the possibility of counting the same fiber twice. On each of these remaining sections (an average of $\sim 11$ sections per animal), all fibers in the caudal spinal cord with a length of $>100 \mu \mathrm{m}$ were counted.

\section{Corticospinal and reticulospinal tract staining}

Sections were first observed under a fluorescent microscope to detect labeling with Micro Ruby. In all animals, fibers were detected rostral to the lesions and, in some cases, in the bridge.

Sections were then processed with avidin-HRP (ABC Elite; Vector

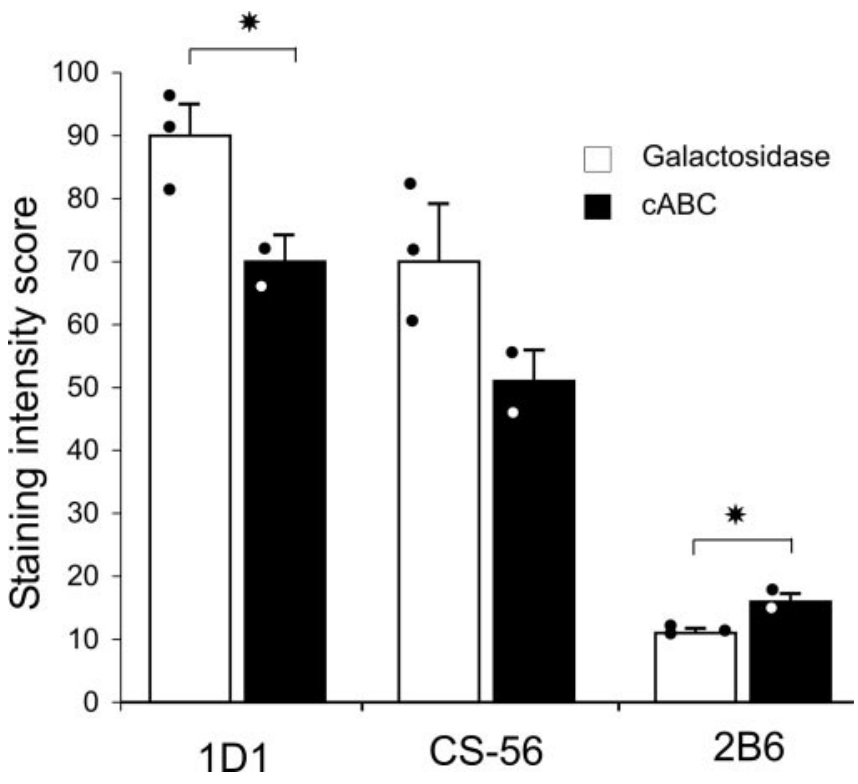

Figure 2. Effectiveness of $\mathrm{CAC}$ application as demonstrated by the use of antibodies against either intact (1D1, CS-56) or digested (2B6) chondroitin sulfate. ${ }^{*} p<0.05$.

Laboratories, Burlingame, CA) followed by a nickel-enhanced diaminobenzidine HRP reaction for the visualization of the BDA tracer, in a semifree-floating technique as described previously (Herzog and Brosamle, 1997). Because both CST and RtST fibers were absent at the caudal end of the bridge or in the caudal stump of the spinal cord, no additional analysis was performed.

\section{Statistics}

Before statistical analysis, exclusion criteria were defined in an attempt to reduce the variability in the groups: animals in which a spinal cord stump (rostral or caudal) had pulled out of the channel, or the injection of the OEG created inflammation and subsequently a lesion that was larger than $50 \%$ of the spinal cord.

Statistical comparisons were performed using GraphPad Prism. Comparisons between the treatment groups were made using the MannWhitney $U$ test. Differences of $p<0.05$ were considered significant; $p<$ 0.01 was considered highly significant. Errors are given as SEM.

\section{Results}

\section{cABC degraded chondroitin sulfate in injured spinal cord}

Two weeks after spinal cord transection, tissue from three animals with grafts and two that also received $\mathrm{CABC}$ was examined to determine whether $\mathrm{CABC}$ had degraded chondroitin sulfate. Three monoclonal antibodies that recognize either digested or intact chondroitin sulfate were used; an increase of 2B6 and reduced CS-56 and 1D1 immunoreactivity at the caudal SC/spinal cord interface indicated $\mathrm{CABC}$ efficacy. The average values of staining intensity were as follows: for Neurocan (1D1), 89.6 \pm 5.1 $(\mathrm{SEM})$ and $70.3 \pm 4.4$; for chondroitin sulfate proteoglycans (CS56), $69.8 \pm 8.6$ and $50.7 \pm 5.3$; for degraded chondroitin sulfate proteoglycans, $10 \pm 0.6$ and $16.2 \pm 1.1$ in the controls and the cABC-treated rats, respectively (Fig. 2).

\section{Partial locomotor recovery followed combined treatment}

Initially, after the spinal cord transection, all animals exhibited complete, flaccid paralysis of the hindlimbs. Slight recovery, represented by spontaneous movements of up to two joints of the hindlegs, was found over the next 5 weeks after injury (Fig. 3C). Rhythmic limb movements were not observed before 6 weeks after lesioning. Because of the extensive laminectomy, many animals suffered from severe lordosis, manifested by a hunched 

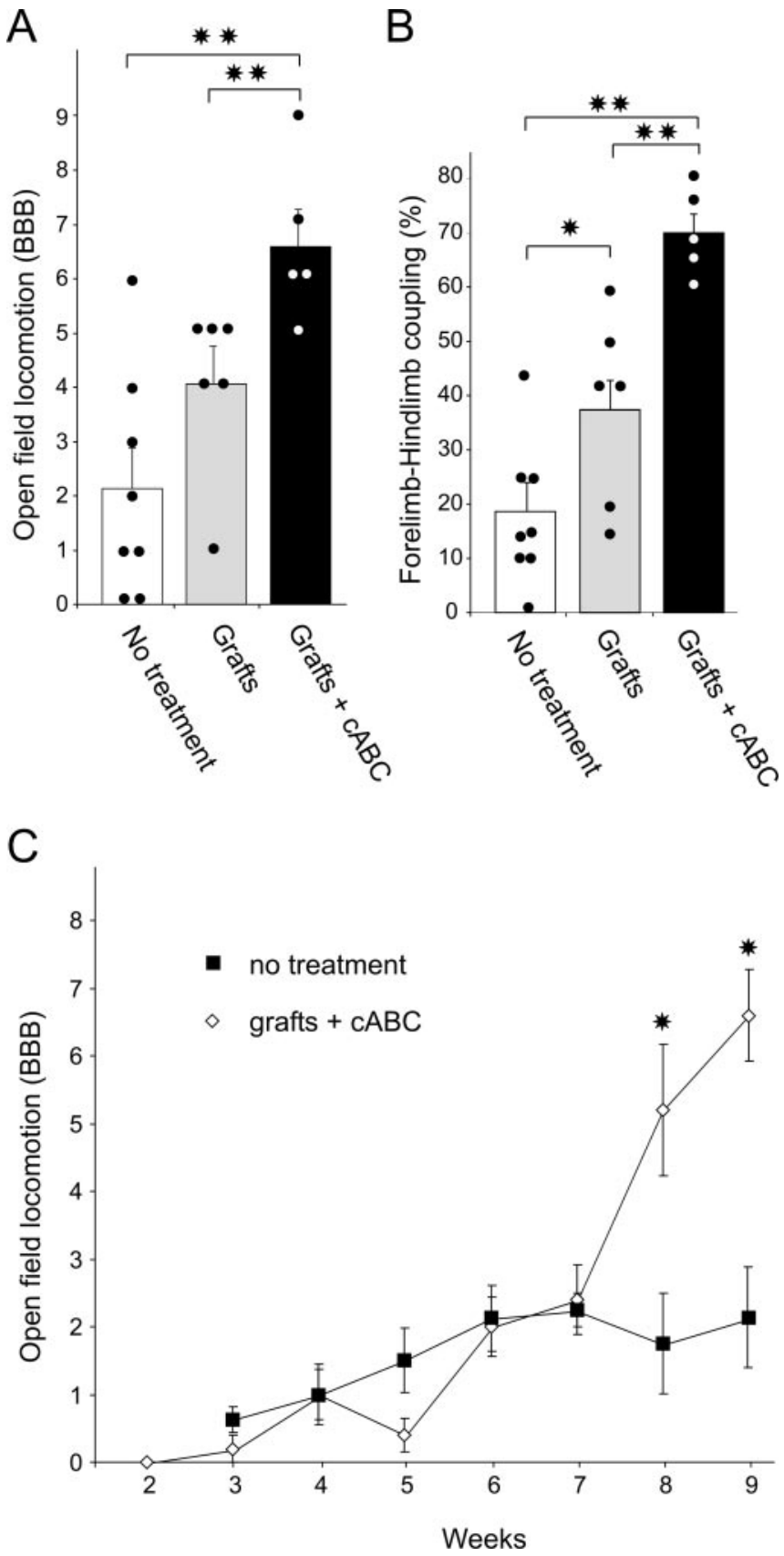

Figure 3. Comparison of the open-field locomotion scores between the different treatment groups quantified with the BBB score $(A)$ and by using the percentage of successful forelimb/ hindlimb coupling $(B)$. C, The time course of recovery shows treatment-induced benefits start to become apparent at 8 weeks after surgery. The dots represent the scores of single animals. ${ }^{*} p<0.05,{ }^{* *} p<0.01$.

posture rostral to the laminectomy site. Some rats also displayed signs of spasticity, including asymmetric muscle tone resulting in asymmetric body posture. When spasticity was quantified using a subjective ranking score (ranging from 0 , no sign of spasticity, to 3 , extensive spasticity), no difference was found between groups (data not shown). Both lordosis and spasticity impacted locomotor ability and consequently limited the animal's functional recovery independently of the ablation of descending axons.

One unexpected finding was that some treated rats exhibited rhythmic and alternating movements of the hindlegs during phases when the animals were standing and the forelimbs did not step. This could be interpreted as spontaneous activity of the pattern generating networks in the lumbar spinal cord. These sequences were excluded from the evaluation of open-field locomotion using the $\mathrm{BBB}$ rating scale.

In none of the animals were the spinal cords pulled out of the channels, but in one animal (grafts only), the rostral injection of OEG resulted in strong inflammation and tissue destruction, creating a second lesion rostral to the transection spanning $\sim 80 \%$ of the spinal cord. Because this fulfilled the exclusion criteria, this animal was removed from the study.

\section{Open-field locomotor score}

Behavioral testing was performed until 9 weeks postlesion (Fig. $3 A)$. The average score in the control group $(n=8)$ was $2.1 \pm 0.7$ (SEM), in the group with transplants was $4 \pm 0.6(n=6)$, and in the $\mathrm{CABC}$ group was $6.6 \pm 0.7(n=5)$. The average $\mathrm{BBB}$ score of the $C A B C$ group was significantly higher than that of the other groups $(p<0.01)$. The group with the transplants did not exhibit any significant improvements in the BBB score when compared with the control group.

No significant difference between the $\mathrm{CABC}$ and control groups was seen until 8 weeks after injury (Fig. $3 C$ ). During the 7 weeks after injury, the BBB scores ranged between 0 and 4 points. The first signs of recovery in locomotor functions were observed and were statistically significant between the $\mathrm{ABC}$ group and the rats with Matrigel only, at 8 weeks. The results indicate that the recovery did not plateau at 9 weeks after the injury, the time point at which testing was discontinued. A representative walking sequence of a rat from the $\mathrm{CABC}$ group with forelimb and hindlimb activity is shown in Figure 4.

\section{Forelimb/hindlimb coupling}

This analysis was added to include information on the tendency of forelimb and hindlimb movements to alternate. Forelimb/ hindlimb coupling is considered in the BBB score only in animals that are able to perform weight-supported plantar stepping. However, in animals with lower locomotor capabilities, this is also an important outcome measure. A measure of the frequency of movements and a relation to forelimb stepping is especially needed after complete SCI. Therefore, the percentage of hindlimb steps after forelimb steps was analyzed.

For assessment, one video recording for each animal at 9 weeks after injury was used. The results are summarized in Figure $3 B$. As in the open-field locomotor score, the untreated rats scored the lowest percentage of forelimb/hindlimb coupling with $18.5 \pm 0.5 \%$. This was statistically different from the group with grafts only $(38.3 \pm 0.7 \%)$. The best coupling was evident in the group with grafts and $\mathrm{CABC}(70 \pm 3.4 \%)$. This improvement was highly significant compared with both the untreated and the grafted groups.

Role of sensory feedback in hindlimb movement

To examine whether hindlimb movements are triggered by sensory feedback resulting from the sliding of hindlegs during forelimb stepping or rather by descending commands from reestablished motor tracts, we examined locomotion on three different surfaces. The first was a smooth Plexiglas surface used for all open-field testing, the second was a Plexiglas surface covered with a thin layer of oil (referred to as a slippery surface), and the third was a carpet (rough surface).

None of the groups on the rough surface were able to verify the prediction that increased cutaneous feedback to the hindlimbs from sliding over the surface would enhance the hindlimb activity. Because the carpet increased friction, the forelimbs were able 
to increase propulsion, and this resulted in a nonquantified, but obvious, increase in walking speed. The forelimb/hindlimb coupling score was either reduced $(p<$ 0.05 in four animals) or statistically unchanged. Walking of the fore limbs on the slippery runway (and if necessary, a slight tilt of the surface) resulted in stationary walking. The rats produced a rhythmic stepping pattern with the forelimbs without moving the rest of the body relative to the surface, thus, strongly reducing sensory feedback to the hindlimbs. Under these conditions, it was hard to motivate the rats to walk, and only very few stepping

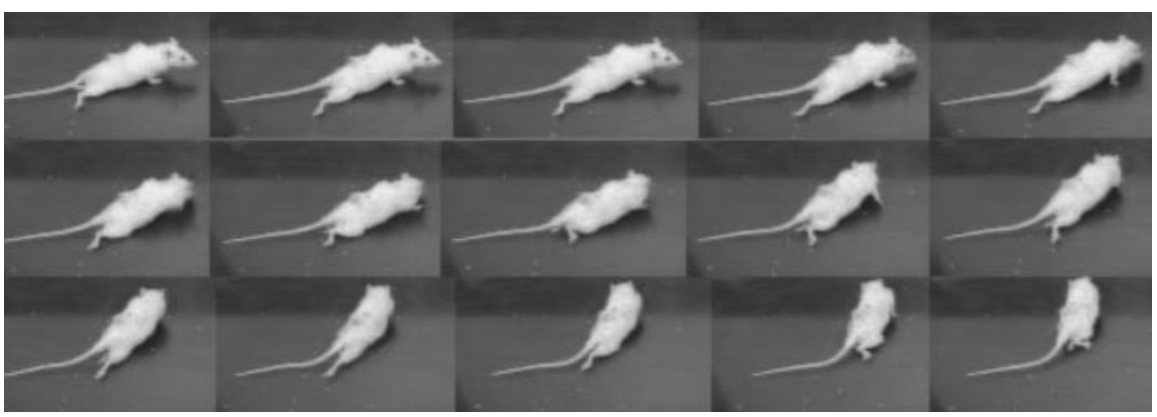

Figure 4. Video sequence from a rat treated with $\mathrm{OEG}$ and Schwann cell grafts as well as with $\mathrm{CABC}$. Note the range of leg motion as well as the alternation between the forelimb and hindlimb movements. The panels are organized in rows from left to right. sequences were recorded. We focused on sequences in which forelimb locomotion was tied to hindlimb activation, because this would support the idea that forelimbs and hindlimbs are coupled and direct descending control is involved in triggering locomotion. Alternating activity of both forelimbs and hindlimbs during stationary walking was found in only two of five rats in the cABC group and in no animals in the remaining groups. This result supports the idea that in animals with alternating forelimb/hindlimb activity, a reconnection of the caudal with the rostral spinal cord has occurred.

\section{Cell grafts increased response to tactile stimuli}

Spinal cord injury is often accompanied by increased responses to mechanical stimuli of cutaneous receptors (allodynia) below the lesion (Siddall et al., 1995; Hutchinson et al., 2004). To test whether the experimental treatments influenced these responses, we tested the reaction to mechanical stimulation with calibrated von Frey hairs at five different locations below the lesion. A general finding was that in all rats, the base of the tail was the most sensitive and most reliably excitable location. Because the relation of excitability at the different locations was consistent between animals, only data gathered from stimulation at the base of the tail are presented. The lowest sensitivity (highest target force to trigger a response) was found in untreated rats (Fig. 5); the average target force at the tip of the von Frey hairs was $0.63 \pm$ $0.1 \mathrm{~g}$. This was significantly higher than in rats with grafts only $(0.31 \pm 0.07 \mathrm{~g})$ and with grafts and $\mathrm{cABC}(0.33 \pm 0.08 \mathrm{~g})$.

\section{Grafts and $\mathrm{CABC}$ enabled serotonergic fiber regeneration}

In this study, we focused on descending axons from three groups of neurons: the hindlimb area of the motor cortex, the medial reticular formation, and the raphe nuclei, which project serotonergic (5-HT-positive) fibers.

Serotonergic fibers were detected within the graft and caudal to it. Even more noteworthy was the abundance of highly branched serotonergic fibers in the caudal spinal cord (Fig. 6A). The quantitative analysis of these fibers caudal to the bridge revealed a high variability within the groups. Because of the large $\mathrm{SD}$, the increase caused by grafting was not significant $(70.1 \pm$ 12.2 , SEM in the rats with grafts only). This increase was further enhanced by the application of CABC $(94 \pm 14.5)$ and was statistically significant when compared with the untreated animals $(15.5 \pm 2.2)$ (Fig. $6 B$ ). Although serotonin in the lumbar spinal cord of injured rats has powerful effects on locomotor function (Ribotta et al., 1998, 2000), no correlation between the number of serotonergic fibers found caudal to the bridge and locomotor recovery was found in our experiment (Fig. 6C).

Detectable tracing of axons of two descending motor tracts

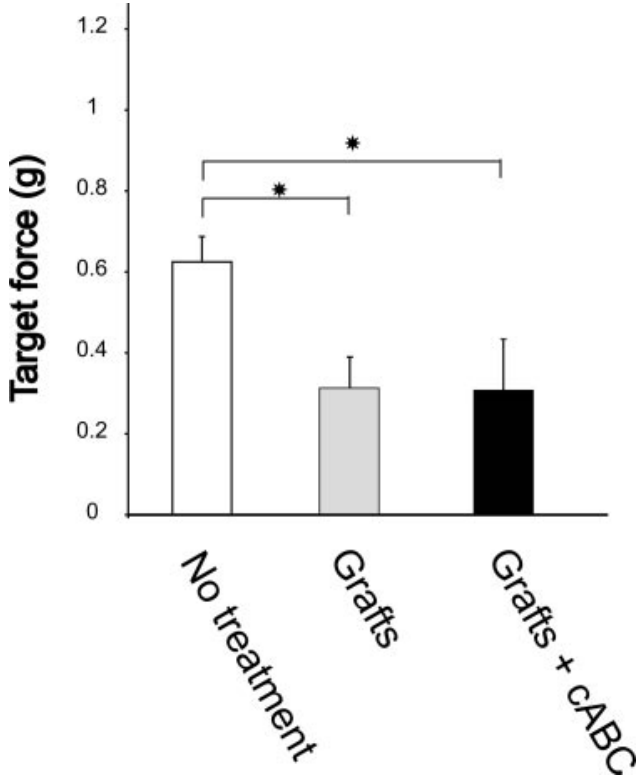

Figure 5. Sensory testing using von Frey hairs at the base of the tail shows increased responsiveness in all of the treated groups. ${ }^{*} p<0.05$.

(CST and RtST) was confirmed rostral to the lesion. Only a few of these traced axons were able to enter the bridge, and none were observed to enter the caudal part of the spinal cord (data not shown).

\section{Myelinated axons and blood vessels in the bridge}

Quantification of myelinated axons and blood vessels was performed in transverse $1 \mu \mathrm{m}$ sections obtained from the center of the bridge. These counts likely include both descending and ascending fibers that cannot be distinguished by this approach (Fig. 7 ). The lowest count was found in the control group with an average of $1009 \pm 237$ (SEM) myelinated axons. In the group with grafts, the average number was (1949 \pm 486$)$, which was not statistically different. The cABC group displayed significantly higher numbers of myelinated axons when compared with the control group (3058 \pm 600$)$ (Fig. 8A).

When the individual axon counts were compared with the functional outcomes (open-field locomotion and forelimb/hindlimb coupling), a significant correlation $(r=0.63)$ was found (Fig. $8 C$ ), indicating that axonal regeneration through the bridge is involved in the observed functional recovery.

The number of blood vessels in the bridge was not statistically increased when comparing either of the groups (Fig. $8 \mathrm{~B}$ ). In- 


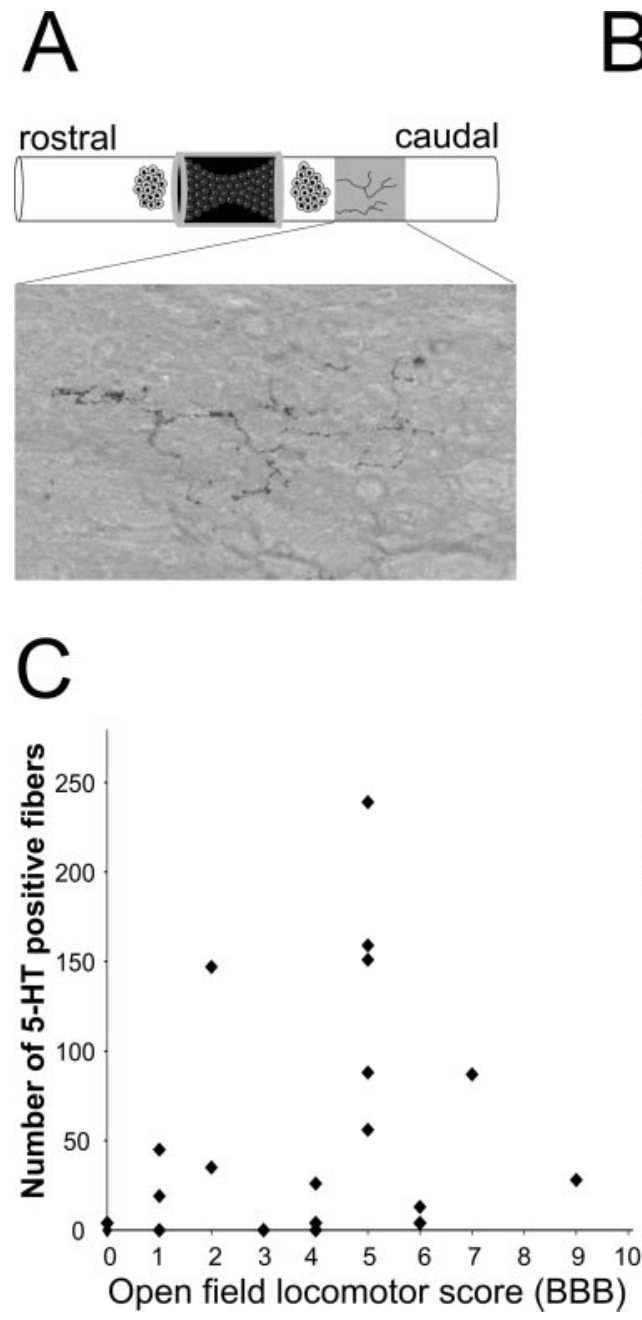

Figure 6. A,5-HT-positive fibers were found to grow into the caudal spinal cord. The quantification of these fibers in the caudal spinal cord is illustrated in $B$. As documented in C, there was no correlation between individual functional recovery and the number of 5 -HT-positive fibers in the caudal spinal cord. ${ }^{*} p<0.05$.
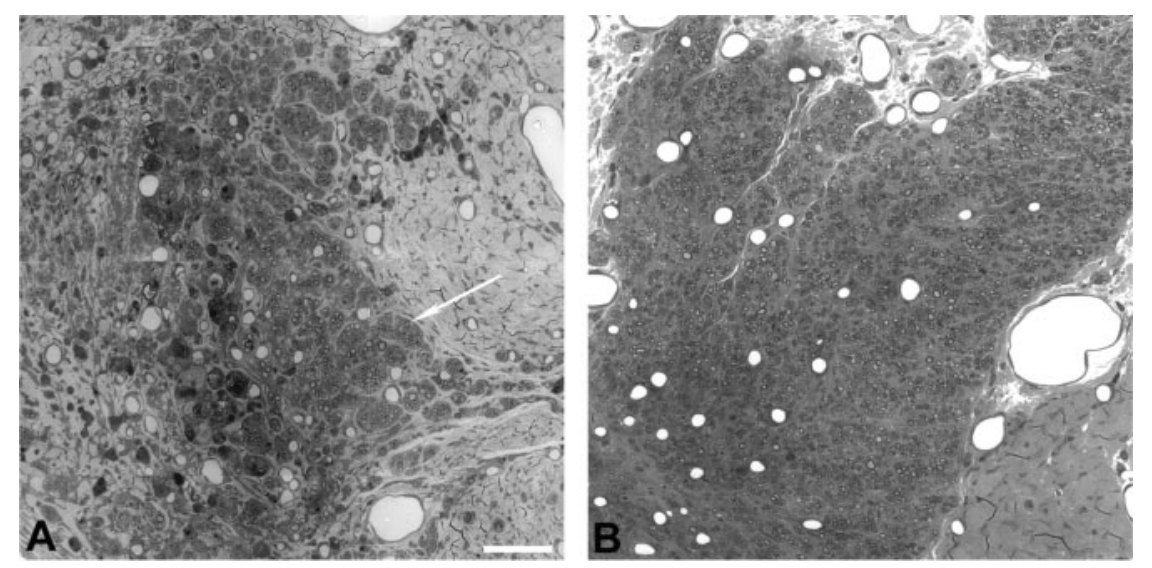

Figure 7. Significantly greater numbers of peripheral-myelinated axons (arrow) are present within the Schwann cell bridge after digestion of CSPGs with chondroitinase $A B C$. Animals with grafts only $(A)$ and animals with grafts and $C A B C(B)$ are shown. Scale bar, $150 \mu \mathrm{m}$.

creased vascularization of the graft would be desired to enhance the viability of the grafted cells within the bridge and to improve support of axonal regeneration. The average numbers of blood vessels in the graft for the groups with no treatment, grafts only, and grafts/cABC were $264 \pm 43$ (SEM), $357 \pm 43$, and $414 \pm 50$, respectively.

\section{Discussion}

Testing the interaction of established experimental treatments is an important step in developing additive, more efficacious treatments for SCI. Our study addresses this need and provides direction for the refinement of future treatments. When compared with untreated rats, only the group of animals subjected to cell grafts and $\mathrm{CABC}$ treatment showed statistically significant improvements in locomotor recovery quantified by both the BBB score and forelimb/hindlimb coupling measurements. Recovery occurred only near the endpoint of the study, at 8 weeks after the injury, a time that would theoretically have been sufficient for axonal regeneration through the graft and into the caudal stump (Xu et al., 1995b, 1997; Steward et al., 2003).

It is very likely that the functional benefits of the current treatments are actually much greater than shown for at least two reasons. First, the time course illustrates that recovery did not plateau at the end of the allotted testing period. A longer experimental time course would have been beneficial in determining the long-term benefits of the combinatory treatment but was not chosen because of small animal numbers in the groups, and the possible loss of animals before fiber tracing had been completed. Second, the laminectomy of three vertebral segments without artificial stabilization resulted in strong lordosis, further hampering locomotor recovery. The hunched body posture would have hindered plantar and weight-supported stepping, even if the nervous system had recovered sufficient motor control. Nevertheless, the results clearly demonstrate that the grafts consisting of SCs and OEG and the application of $\mathrm{CABC}$ have additive effects. Our results are the first to demonstrate the beneficial effects of $\mathrm{CABC}$ on axonal regeneration after complete spinal cord transection and support previous reports in which $\mathrm{CABC}$ application also has shown salutary effects after brain injury (Moon et al., 2001) and incomplete lesions of the spinal cord (Bradbury et al., 2002; Yick et al., 2003). The application of cABC appears especially suited when applied in conjunction with grafted tissue, because scar tissue at the graft-host interface represents a barrier for axons to grow into and through the graft (Chau et al., 2004).

It is noteworthy that one control animal reached a BBB score of 6 and its recovery progressed faster than in the treated group. This recovery was unexpected, because the surgery eliminated 

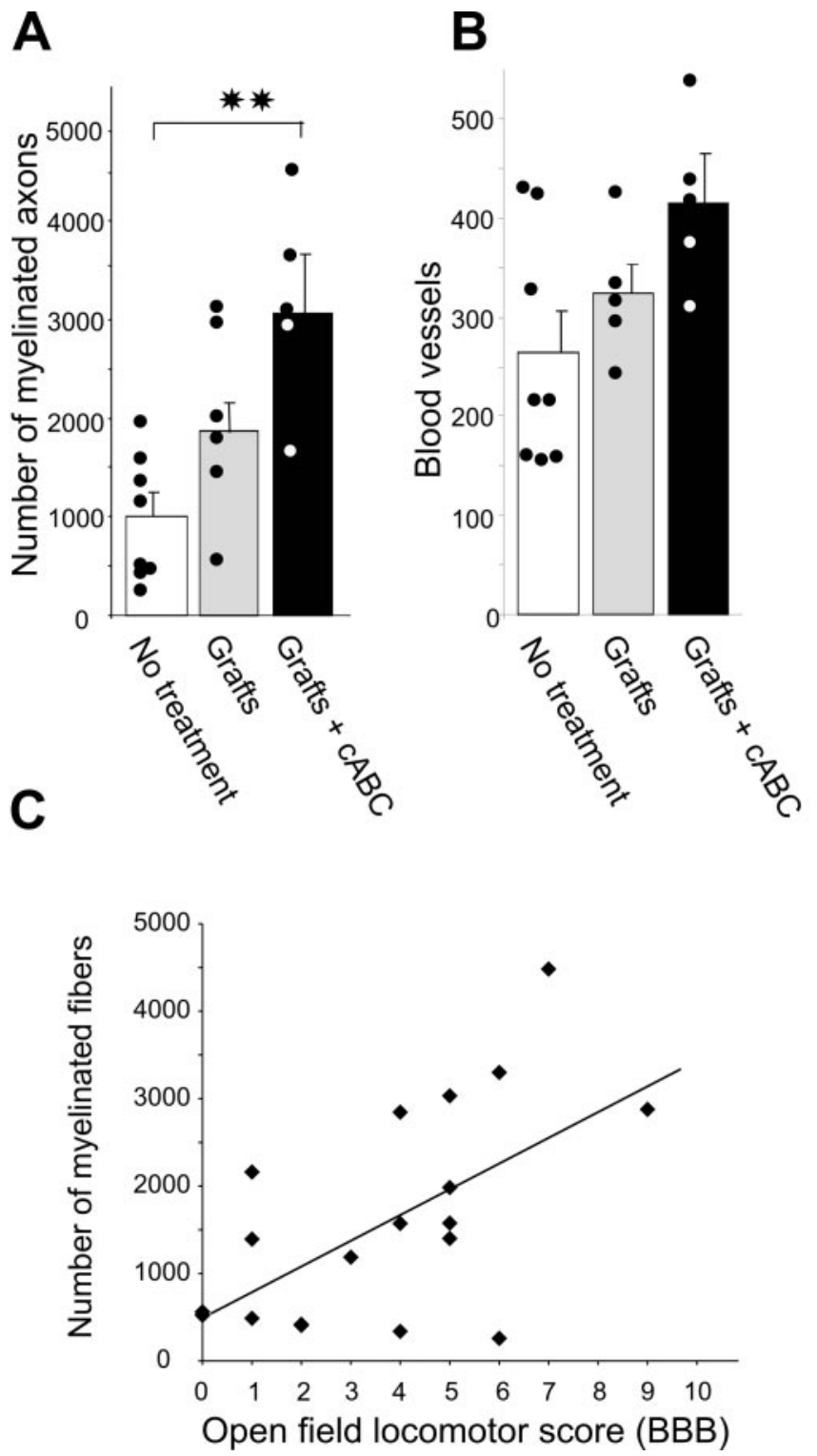

Figure 8. Counts of myelinated axons in the middle of the bridge showed a significant ( $p<$ 0.01 ) increase $(A)$ in the group with grafts and $C A B C$. $B$, The number of blood vessels in the bridge was not different between the groups. $C$, There was a significant correlation $\left(r^{2}=0.63\right)$ between individual functional recovery and the number of myelinated axons.

any chance of axonal sparing. Even a relesion 9 weeks later could not reduce hindlimb activity. This phenomenon illustrates the plastic capabilities of the spinal networks controlling locomotion (for review, see Pearson, 2000; Edgerton et al., 2001; Rossignol et al., 2002).

Another unexpected result was the considerable number of myelinated axons and serotonergic axons observed in Matrigelonly grafts; these fibers were not found in Matrigel-only bridges in previous studies (Xu et al., 1997). This and the finding that in none of the animals was the spinal cord pulled out of the channel may be attributable to the new technique for implanting an SC bridge used in this study. Inserting the channel first, then adding the SCs in fluid Matrigel through windows on the dorsal surface of the channel, may enable better apposition between the SCs and the spinal cord stumps. It has been reported that HRP-labeled CST axons enter a graft of collagen when the collagen is introduced in fluid form, which self-assembles in situ but does not enter the matrix when the collagen is implanted in solid gel form (Joosten et al., 1995). This study also suggested that when the implant is in fluid form, it may better conform to the surface of the cord stump.

A major question after experimental treatments to repair the injured spinal cord is whether observed functional recovery is caused by regenerated fibers reconnecting to appropriate targets below the lesion or changes in existing circuitries above and below the lesion (for review, see Fouad and Pearson, 2004). Whereas some studies have reported axonal regeneration and functional recovery after complete SCI because of treatment (Cheng et al., 1996; Ramón-Cueto et al., 2000), very few have provided evidence of reconnection. One link between regeneration and functional recovery is histological evidence of fibers growing through the graft and into the caudal stump of the spinal cord. Traced fibers of the CST and the RtST were found to enter the SC bridge, but none were found to grow through and out of the bridge into the contiguous caudal cord.

In contrast, in rats with grafted cells in our study, 5-HT fibers that grew through the bridge and projected into the caudal stump were found in abundance. This confirms previous experiments in which SC bridges combined with OEG grafts led to the presence of 5-HT fibers caudal to the bridge occupying a complete transection gap (Ramón-Cueto et al., 1998). Because the application of serotonin or the grafting of serotonin-secreting cells to the caudal spinal cord is capable of promoting significant locomotor recovery (Ribotta et al., 2000; Antri et al., 2002), it seems counterintuitive that no correlation between an increased number of serotonergic fibers and locomotor recovery was found. Possible explanations could be that even greater numbers of regenerating serotonergic fibers are necessary to promote locomotor recovery, they did not grow far enough into the lumbar cord, or the fibers were not functional.

The significant correlation that we found between functional recovery and the number of myelinated axons in the center of the bridge suggests that fibers other than CST, RtST, or serotonergic axons were involved in the observed recovery. Plausible candidates are axons of propriospinal interneurons that are known to grow through SC bridges (Xu et al., 1995b, 1997); the interneurons can be used as relays for lesioned axons sprouting rostral to a lesion (Fouad et al., 2001; Raineteau and Schwab, 2001; Raineteau et al., 2001; Bareyre et al., 2004). Propriospinal interneurons were not traced in the present study and should be monitored using retrograde tracers in future work. An alternative approach to confirm the relationship between regeneration and functional recovery, a relesion of the spinal cord, was performed only in one rat, because it would have interfered with the anterograde tracing used in our study.

A finding supporting a reestablished connection via the lesion site comes from behavioral testing on a slippery surface. During "stationary" forelimb stepping, sensory feedback to the hindlimbs was reduced to a minimum, because no sliding over the surface occurred. Under these circumstances, the hindlimbs of a few rats with high locomotor scores were activated and alternating with the forelimbs, indicating that both forelimb and hindlimb stepping was triggered by descending input. Promoting axonal regeneration in the injured spinal cord does not only involve descending motor axons. Sprouting and growth of sensory fibers will also be enhanced. Although our study did not monitor sprouting of sensory fibers, we assessed responses to tactile cutaneous stimuli in dermatomes caudal to the lesion. The finding that treated rats presented significantly increased sensitivity to tactile stimuli impacts the clinical value of regeneration- 
promoting treatments, because increased pain after a treatment would be undesirable. However, our results do not necessarily have to be interpreted as increased pain or allodynia. Paralyzed rats showed signs comparable with spasticity in human patients, and thus the increased responses to tactile stimuli could simply be a sign of increased spasticity triggered by disinhibition of spinal pathways (Calancie et al., 1993) or changes in neuronal properties (Bennett et al., 2004; Li et al., 2004). Increased sensory feedback has been suggested to accentuate locomotor recovery after SCI (Pearson, 2001). Changes in sensitivity as reported above would predict enhanced stepping movements when walking on a rough surface because of greater levels of cutaneous feedback. However, this was not the case. Rather, it appears that changes in ground texture during a walking sequence initiate reflex-like stepping.

The implications of the current study form an important stepping stone toward the development of a combined treatment for SCI. Additional treatment strategies that involve the neutralization of myelin-associated inhibitors by blocking Nogo A, Nogo 66, MAG, and oligodendrocyte-myelin glycoprotein (Merkler et al., 2001; GrandPre et al., 2002; Liu et al., 2002), the application of growth and survival-promoting neurotrophic factors (Schnell et al., 1994; Mocchetti and Wrathall, 1995; Xu et al., 1995a; Kobayashi et al., 1997; Ye and Houle, 1997; Menei et al., 1998; Bamber et al., 2001; Blesch and Tuszynski, 2003), and the stimulation of the intrinsic capacity of neurons to grow (Dergham et al., 2002; Neumann et al., 2002; Qiu et al., 2002; Fournier et al., 2003; Lu et al., 2004; Nikulina et al., 2004; Pearse et al., 2004a) should be integrated and tested for their compatibility after complete transection of the spinal cord.

\section{References}

Aebischer P, Guenard V, Winn SR, Valentini RF, Galletti PM (1988) Blindended semipermeable guidance channels support peripheral nerve regeneration in the absence of a distal nerve stump. Brain Res 454:179-187.

Antri M, Orsal D, Barthe JY (2002) Locomotor recovery in the chronic spinal rat: effects of long-term treatment with a $5-\mathrm{HT}_{2}$ agonist. Eur J Neurosci 16:467-476.

Bamber NI, Li H, Lu X, Oudega M, Aebischer P, Xu XM (2001) Neurotrophins BDNF and NT-3 promote axonal re-entry into the distal host spinal cord through Schwann cell-seeded mini-channels. Eur J Neurosci 13:257-268.

Bareyre FM, Kerschensteiner M, Raineteau O, Mettenleiter TC, Weinmann O, Schwab ME (2004) The injured spinal cord spontaneously forms a new intraspinal circuit in adult rats. Nat Neurosci 7:269-277.

Basso DM, Beattie MS, Bresnahan JC (1995) A sensitive and reliable locomotor rating scale for open field testing in rats. J Neurotrauma 12:1-21.

Bennett DJ, Sanelli L, Cooke CL, Harvey PJ, Gorassini MA (2004) Spastic long-lasting reflexes in the awake rat after sacral spinal cord injury. J Neurophysiol 91:2247-2258.

Blesch A, Tuszynski MH (2003) Cellular GDNF delivery promotes growth of motor and dorsal column sensory axons after partial and complete spinal cord transections and induces remyelination. J Comp Neurol 467:403-417.

Bradbury EJ, Moon LD, Popat RJ, King VR, Bennett GS, Patel PN, Fawcett JW, McMahon SB (2002) Chondroitinase ABC promotes functional recovery after spinal cord injury. Nature 416:636-640.

Bregman BS, McAtee M, Dai HN, Kuhn PL (1997) Neurotrophic factors increase axonal growth after spinal cord injury and transplantation in the adult rat. Exp Neurol 148:475-494.

Brosamle C, Huber AB, Fiedler M, Skerra A, Schwab ME (2000) Regeneration of lesioned corticospinal tract fibers in the adult rat induced by a recombinant, humanized IN-1 antibody fragment. J Neurosci 20:8061-8068.

Bunge MB, Pearse DD (2003) Transplantation strategies to promote repair of the injured spinal cord. J Rehabil Res Dev 40:55-62.

Calancie B, Broton JG, Klose KJ, Traad M, Difini J, Ayyar DR (1993) Evidence that alterations in presynaptic inhibition contribute to segmental hypo- and hyperexcitability after spinal cord injury in man. Electroencephalogr Clin Neurophysiol 89:177-186.

Chau CH, Shum DK, Li H, Pei J, Lui YY, Wirthlin L, Chan YS, Xu XM (2004) Chondroitinase $\mathrm{ABC}$ enhances axonal regrowth through Schwann cellseeded guidance channels after spinal cord injury. FASEB J 18:194-196.

Chen A, Xu XM, Kleitman N, Bunge MB (1996) Methylprednisolone administration improves axonal regeneration into Schwann cell grafts in transected adult rat thoracic spinal cord. Exp Neurol 138:261-276.

Cheng H, Cao Y, Olson L (1996) Spinal cord repair in adult paraplegic rats: partial restoration of hind limb function. Science 273:510-513.

Coumans JV, Lin TT, Dai HN, MacArthur L, McAtee M, Nash C, Bregman BS (2001) Axonal regeneration and functional recovery after complete spinal cord transection in rats by delayed treatment with transplants and neurotrophins. J Neurosci 21:9334-9344.

Dergham P, Ellezam B, Essagian C, Avedissian H, Lubell WD, McKerracher L (2002) Rho signaling pathway targeted to promote spinal cord repair. J Neurosci 22:6570-6577.

Edgerton VR, Leon RD, Harkema SJ, Hodgson JA, London N, Reinkensmeyer DJ, Roy RR, Talmadge RJ, Tillakaratne NJ, Timoszyk W, Tobin A (2001) Retraining the injured spinal cord. J Physiol (Lond) 533:15-22.

Fawcett JW, Asher RA (1999) The glial scar and central nervous system repair. Brain Res Bull 49:377-391.

Fouad K, Pearson K (2004) Restoring walking after spinal cord injury. Prog Neurobiol 73:107-126.

Fouad K, Pedersen V, Schwab ME, Brosamle C (2001) Cervical sprouting of corticospinal fibers after thoracic spinal cord injury accompanies shifts in evoked motor responses. Curr Biol 11:1766-1770.

Fournier AE, Takizawa BT, Strittmatter SM (2003) Rho kinase inhibition enhances axonal regeneration in the injured CNS. J Neurosci 23:1416-1423.

GrandPre T, Li S, Strittmatter SM (2002) Nogo-66 receptor antagonist peptide promotes axonal regeneration. Nature 417:547-551.

Guth L, Zhang Z, Roberts E (1994) Key role for pregnenolone in combination therapy that promotes recovery after spinal cord injury. Proc Natl Acad Sci USA 91:12308-12312.

Herzog A, Brosamle C (1997) "Semifree-floating" treatment: a simple and fast method to process consecutive sections for immunohistochemistry and neuronal tracing. J Neurosci Methods 72:57-63.

Hutchinson KJ, Gomez-Pinilla F, Crowe MJ, Ying Z, Basso DM (2004) Three exercise paradigms differentially improve sensory recovery after spinal cord contusion in rats. Brain 127:1403-1414.

Joosten EA, Bar PR, Gispen WH (1995) Collagen implants and corticospinal axonal growth after mid-thoracic spinal cord lesion in the adult rat. J Neurosci Res 41:481-490.

Kobayashi NR, Fan DP, Giehl KM, Bedard AM, Wiegand SJ, Tetzlaff W (1997) BDNF and NT-4/5 prevent atrophy of rat rubrospinal neurons after cervical axotomy, stimulate GAP- 43 and T $\alpha 1$-tubulin mRNA expression, and promote axonal regeneration. J Neurosci 17:9583-9595.

Li S, Strittmatter SM (2003) Delayed systemic Nogo-66 receptor antagonist promotes recovery from spinal cord injury. J Neurosci 23:4219-4227.

Li Y, Field PM, Raisman G (1997) Repair of adult rat corticospinal tract by transplants of olfactory ensheathing cells. Science 277:2000-2002.

Li Y, Harvey PJ, Li X, Bennett DJ (2004) Spastic long-lasting reflexes of the chronic spinal rat studied in vitro. J Neurophysiol 91:2236-2246.

Liu BP, Fournier A, GrandPre T, Strittmatter SM (2002) Myelin-associated glycoprotein as a functional ligand for the Nogo-66 receptor. Science 297:1190-1193.

Lu P, Yang H, Jones LL, Filbin MT, Tuszynski MH (2004) Combinatorial therapy with neurotrophins and cAMP promotes axonal regeneration beyond sites of spinal cord injury. J Neurosci 24:6402-6409.

Meijs MFL, Timmers L, Pearse DD, Tresco PA, Bates ML, Joosten EAJ, Bunge MB, Oudega M (2004) Basic fibroblast growth factor promotes neuronal survival and angiogenesis but not axonal regeneration and myelination in a Schwann cell bridge in the transected adult rat thoracic spinal cord. J Neurotrauma 21:1415-1430.

Menei P, Montero-Menei C, Whittemore SR, Bunge RP, Bunge MB (1998) Schwann cells genetically modified to secrete human BDNF promote enhanced axonal regrowth across transected adult rat spinal cord. Eur J Neurosci 10:607-621.

Merkler D, Metz GA, Raineteau O, Dietz V, Schwab ME, Fouad K (2001) Locomotor recovery in spinal cord-injured rats treated with an antibody 
neutralizing the myelin-associated neurite growth inhibitor Nogo-A. J Neurosci 21:3665-3673.

Mocchetti I, Wrathall JR (1995) Neurotrophic factors in central nervous system trauma. J Neurotrauma 12:853-870.

Moon LD, Asher RA, Rhodes KE, Fawcett JW (2001) Regeneration of CNS axons back to their target following treatment of adult rat brain with chondroitinase ABC. Nat Neurosci 4:465-466.

Moon LD, Asher RA, Rhodes KE, Fawcett JW (2002) Relationship between sprouting axons, proteoglycans and glial cells following unilateral nigrostriatal axotomy in the adult rat. Neuroscience 109:101-117.

Morrissey TK, Kleitman N, Bunge RP (1991) Isolation and functional characterization of Schwann cells derived from adult peripheral nerve. J Neurosci 11:2433-2442.

Mu X, Azbill RD, Springer JE (2000) Riluzole and methylprednisolone combined treatment improves functional recovery in traumatic spinal cord injury. J Neurotrauma 17:773-780.

Neumann S, Bradke F, Tessier-Lavigne M, Basbaum AI (2002) Regeneration of sensory axons within the injured spinal cord induced by intraganglionic cAMP elevation. Neuron 34:885-893.

Nikulina E, Tidwell JL, Dai HN, Bregman BS, Filbin MT (2004) The phosphodiesterase inhibitor rolipram delivered after a spinal cord lesion promotes axonal regeneration and functional recovery. Proc Natl Acad Sci USA 101:8786-8790.

Novikova LN, Novikov LN, Kellerth JO (2002) Differential effects of neurotrophins on neuronal survival and axonal regeneration after spinal cord injury in adult rats. J Comp Neurol 452:255-263.

Novikova LN, Novikov LN, Kellerth JO (2003) Biopolymers and biodegradable smart implants for tissue regeneration after spinal cord injury. Curr Opin Neurol 16:711-715.

Paxinos G, Watson C (1986) The rat brain in stereotaxic coordinates. San Diego: Academic.

Pearse DD (2004) Targeting intracellular signaling molecules within the neuron to promote repair after spinal cord injury. Top Spinal Cord Inj Rehabil 10:1-16.

Pearse DD, Pereira FC, Marcillo AE, Bates ML, Berrocal YA, Filbin MT, Bunge MB (2004a) cAMP and Schwann cells promote axonal growth and functional recovery after spinal cord injury. Nat Med 10:610-616.

Pearse DD, Marcillo AE, Oudega M, Lynch MP, Wood PM, Bunge MB (2004b) Transplantation of Schwann cells and olfactory ensheathing glia after spinal cord injury: can pretreatment with methylprednisolone and interleukin-10 enhance recovery? J Neurotrauma 21:1223-1239.

Pearson KG (2000) Plasticity of neuronal networks in the spinal cord: modifications in response to altered sensory input. Prog Brain Res 128:61-70.

Pearson KG (2001) Could enhanced reflex function contribute to improving locomotion after spinal cord repair? J Physiol (Lond) 533:75-81.

Qiu J, Cai D, Dai H, McAtee M, Hoffman PN, Bregman BS, Filbin MT (2002) Spinal axon regeneration induced by elevation of cyclic AMP. Neuron 34:895-903.

Raineteau O, Schwab ME (2001) Plasticity of motor systems after incomplete spinal cord injury. Nat Rev Neurosci 2:263-273.

Raineteau O, Fouad K, Noth P, Thallmair M, Schwab ME (2001) Functional switch between motor tracts in the presence of the $\mathrm{mAb} I N-1$ in the adult rat. Proc Natl Acad Sci USA 98:6929-6934.

Ramón-Cueto A, Plant GW, Avila J, Bunge MB (1998) Long distance axonal regeneration in the transected adult rat spinal cord is promoted by ensheathing glia transplants. J Neurosci 18:3803-3815.

Ramón-Cueto A, Cordero MI, Santos-Benito FF, Avila J (2000) Functional recovery of paraplegic rats and motor axon regeneration in their spinal cords by olfactory ensheathing glia. Neuron 25:425-435.

Ribotta MG, Orsal D, Feraboli-Lohnherr D, Privat A, Provencher J, Rossignol S (1998) Kinematic analysis of recovered locomotor movements of the hindlimbs in paraplegic rats transplanted with monoaminergic embryonic neurons. Ann NY Acad Sci 860:521-523.

Ribotta MG, Provencher J, Feraboli-Lohnherr D, Rossignol S, Privat A, Orsal D (2000) Activation of locomotion in adult chronic spinal rats is achieved by transplantation of embryonic raphe cells reinnervating a precise lumbar level. J Neurosci 20:5144-5152.

Rossignol S, Bouyer L, Barthelemy D, Langlet C, Leblond H (2002) Recovery of locomotion in the cat following spinal cord lesions. Brain Res Brain Res Rev 40:257-266.

Schnell L, Schneider R, Kolbeck R, Barde YA, Schwab ME (1994) Neurotrophin-3 enhances sprouting of corticospinal tract during development and after adult spinal cord lesion. Nature 367:170-173.

Schwab ME, Bartholdi D (1996) Degeneration and regeneration of axons in the lesioned spinal cord. Physiol Rev 76:319-370.

Siddall P, Xu CL, Cousins M (1995) Allodynia following traumatic spinal cord injury in the rat. NeuroReport 6:1241-1244.

Silver J, Miller JH (2004) Regeneration beyond the glial scar. Nat Rev Neurosci 5:146-156.

Steward O, Zheng B, Tessier-Lavigne M (2003) False resurrections: distinguishing regenerated from spared axons in the injured central nervous system. J Comp Neurol 459:1-8.

Takami T, Oudega M, Bates ML, Wood PM, Kleitman N, Bunge MB (2002) Schwann cell but not olfactory ensheathing glia transplants improve hindlimb locomotor performance in the moderately contused adult rat thoracic spinal cord. J Neurosci 22:6670-6681.

Weidner N, Blesch A, Grill RJ, Tuszynski MH (1999) Nerve growth factorhypersecreting Schwann cell grafts augment and guide spinal cord axonal growth and remyelinate central nervous system axons in a phenotypically appropriate manner that correlates with expression of L1. J Comp Neurol 413:495-506.

West NR, Collins GH (1989) Cellular changes during repair of a cryogenic spinal cord injury in the rat: an electron microscopic study. J Neuropathol Exp Neurol 48:94-108.

Woerly S, Doan VD, Sosa N, de Vellis J, Espinosa-Jeffrey A (2004) Prevention of gliotic scar formation by NeuroGel allows partial endogenous repair of transected cat spinal cord. J Neurosci Res 75:262-272.

Xu XM, Guenard V, Kleitman N, Aebischer P, Bunge MB (1995a) A combination of BDNF and NT-3 promotes supraspinal axonal regeneration into Schwann cell grafts in adult rat thoracic spinal cord. Exp Neurol 134:261-272.

Xu XM, Guenard V, Kleitman N, Bunge MB (1995b) Axonal regeneration into Schwann cell-seeded guidance channels grafted into transected adult rat spinal cord. J Comp Neurol 351:145-160.

Xu XM, Chen A, Guenard V, Kleitman N, Bunge MB (1997) Bridging Schwann cell transplants promote axonal regeneration from both the rostral and caudal stumps of transected adult rat spinal cord. J Neurocytol 26:1-16.

Ye JH, Houle JD (1997) Treatment of the chronically injured spinal cord with neurotrophic factors can promote axonal regeneration from supraspinal neurons. Exp Neurol 143:70-81.

Yick LW, Cheung PT, So KF, Wu W (2003) Axonal regeneration of Clarke's neurons beyond the spinal cord injury scar after treatment with chondroitinase ABC. Exp Neurol 182:160-168. 